\title{
Returning to a Patient-Centered Approach in the Management of Hypothyroidism
}

\author{
Jill Scbneiderban, MD \\ Suzanna Zick, ND, MPH \\ University of Michigan Medical School, Ann Arbor, Michigan
}

Ann Fam Med 2020;18:388-389. https://doi.org/10.1370/afm.2602.

$\mathrm{S}$ hared decision making is an important aspect of high-quality health care and incorporates understanding patients' beliefs around how medication works, the potential side effects, and expected benefits. Gaining this understanding helps to guide the decision of which medications most closely align with patients' beliefs and expectations. This may be especially important for improving adherence to chronic medications, and in particular, for thyroid medication where 40 to $50 \%$ of patients do not take their medication as prescribed. ${ }^{1}$

The historical context sheds light on this topic by highlighting the shift from patient-centered symptom management to one based on laboratory values, which diminishes room for the patient experience. Before the 1970s, hypothyroidism was treated with desiccated thyroid products (dehydrated porcine or bovine thyroid). Desiccated thyroid products contain a combination of thyroxine (T4) and triiodothyronine (T3) in an approximately $4: 1$ ratio, and historically were titrated to the cessation of symptoms, while monitoring for thyrotoxicosis. ${ }^{2}$ In the 1970 s a shift occurred in both the supplementation and measuring of T3 and T4, which led to better assessment of what happened with replacement of individual synthetic hormones. It was noted that replacing T3 alone led to large swings in T3 levels shortly after taking the drug which did not mimic physiologic levels seen in euthyroid individuals. When, however, synthetic T4 (levothyroxine) was introduced it resulted in T3 levels that were normalized throughout the day instead of fluctuating. Thus,

Conflicts of interest: authors report none.

\section{CORRESPONDING AUTHOR}

Jill Schneiderhan, MD

University of Michigan Medical School

1301 Catherine St.

Ann Arbor, Michigan 48109

jillsch@med.umich.edu the idea that peripheral tissue conversion supplied all the T3 that was needed to normalize thyroid function took hold. This was confirmed by the development of the assay for thyroid stimulating hormone (TSH), which measured stability of thyroid function over time, and remained steady with levothyroxine-only dosing. As such, the end goal for the treatment of hypothyroidism shifted from symptom control to achieving a normal TSH. ${ }^{3}$ The focus on normal TSH, and concerns over the lack of batch-to-batch consistency in desiccated thyroid products (they are standardized for iodine content) led to the use of desiccated thyroid products being actively discouraged. ${ }^{4}$

This one-size-fits-all approach for treating hypothyroidism does not work, however, for all patients. Emerging evidence shows that for many patients, symptoms persist despite normal TSH values. ${ }^{5}$ In a qualitative study, patients who continued to feel unwell with normalized TSH reported feeling that their physicians were not willing to look further into why their symptoms were persisting. ${ }^{6}$ In addition, patients often reported that the vague nature of their symptoms along with lack of control over their symptoms, leave them feeling invalidated and without answers. ${ }^{7}$ In fact, these ongoing symptoms may have a physiologic cause. New information has emerged that conversion of T4 to T3 by exogenous tissue is more complex than previously described. For instance, patients on levothyroxine alone have higher $\mathrm{T} 4$, lower $\mathrm{T} 3{ }^{8}$ lower energy expenditure, ${ }^{9}$ and ongoing abnormalities of lipid metabolism ${ }^{8}$; all pointing to a lack of appropriate thyroid metabolism. Further, in thyroidectomy patients the amount of supplementation needed to achieve normalization of T3 levels is such that it leads to suppression of $\mathrm{TSH}_{1}{ }^{10,11}$ which may explain why some patients lack complete resolution with normal TSH and feel resolution of symptoms with suppressed TSH levels.

One possible way of addressing these imbalances and persistence of symptoms is the addition of T3, 
which desiccated thyroid products naturally contain. A barrier to their use, however, is the ongoing concern that TSH will not be consistently maintained within normal ranges. Kuye et $\mathrm{a}^{12}$ has contributed to our understanding of this concern in their retrospective matched cohort study in this issue. They begin a much-needed investigation into whether patients prescribed synthetic levothyroxine compared with desiccated thyroid had differences in TSH stability over the course of 3 years. Their results in 870 hypothyroid patients matched for age, sex, and ethnicity showed no difference in longitudinal TSH stability between desiccated thyroid products and synthetic levothyroxine, and despite more variation in visit-to-visit TSH levels variability in the patients taking desiccated thyroid, all patients regardless of the thyroid medication were euthyroid $79 \%$ of the time.

Further prospective studies are needed to confirm these results and to explore differences in more diverse patient populations, such as Hashimoto's thyroiditis as well as on quality of life and other important patientreported outcomes such as fatigue and weight gain. This study does, however, provide helpful information that desiccated thyroid products are a reasonable choice for treating some hypothyroid patients. Keeping desiccated thyroid medications as an option in our tool kit will allow for improved shared decision making, while allowing for patient preference, and offer an option for those patients who remain symptomatic on levothyroxine monotherapy.

To read or post commentaries in response to this article, see it online at https://www.AnnFamMed.org/content/18/5/388.

Key words: hypothyroidism; primary health care; shared decision making

Submitted July 22, 2020; accepted August 5, 2020.

\section{References}

1. Hepp Z, Wyne K, Manthena SR, Wang S, Gossain V. Adherence to thyroid hormone replacement therapy: a retrospective, claims database analysis. Curr Med Res Opin. 2018;34(9):1673-1678.

2. Idrees T, Palmer S, Maciel RMB, Bianco AC. Liothyronine and desiccated thyroid extract in the treatment of hypothyroidism. [published online ahead of print May 12, 2020]. Thyroid. doi: 10.1089/ thy. 2020.0153.

3. Hennessey JV. The emergence of levothyroxine as a treatment for hypothyroidism. Endocrine. 2017;55(1):6-18.

4. MacGregor AG. Why does anybody use thyroid B.P.? Lancet. 1961; 1(7172):329-332.

5. Saravanan P, Chau WF, Roberts N, Vedhara K, Greenwood R, Dayan CM. Psychological well-being in patients on 'adequate' doses of I-thyroxine: results of a large, controlled community-based questionnaire study. Clin Endocrinol (Oxf). 2002;57(5):577-585.

6. Dew R, King K, Okosieme OE, et al. Patients' attitudes and perceptions towards treatment of hypothyroidism in general practice: an in-depth qualitative interview study. BJGP Open. 2017;1(2):bjgpopen 17X100977.

7. Nexø MA, Watt T, Cleal B, et al. Exploring the experiences of people with hypo- and hyperthyroidism. Qualitative Health Research. 2015;25(7):945-953.

8. Peterson SJ, McAninch EA, Bianco AC. Is a normal TSH synonymous with "euthyroidism" in levothyroxine monotherapy? J Clin Endocrinol Metab. 2016;101(12):4964-4973.

9. Samuels MH, Kolobova I, Smeraglio A, Peters D, Purnell JQ, Schuff KG. Effects of levothyroxine replacement or suppressive therapy on energy expenditure and body composition. Thyroid. 2016;26(3): 347-355.

10. Gullo D, Latina A, Frasca F, Le Moli R, Pellegriti G, Vigneri R. Levothyroxine monotherapy cannot guarantee euthyroidism in all athyreotic patients. PLoS One. 2011;6(8):e22552.

11. Ito M, Miyauchi A, Morita S, et al. TSH-suppressive doses of levothyroxine are required to achieve preoperative native serum triiodothyronine levels in patients who have undergone total thyroidectomy. Eur J Endocrinol. 2012;167(3):373-378.

12. Kuye R, Riggs C, King J, et al. Thyroid stimulating hormone stability in patients prescribed synthetic or desiccated thyroid products: a retrospective study. Ann Fam Med. 2020;18(5):452-454.

\section{CORRECTION}

Ann Fam Med 2020;18:389. https://doi.org/10.1370/afm.2581.

In Doubeni CA, Wilkinson JM, Korsen N, Midthun DE. Lung cancer screening guidelines implementation in primary care: a call to action. Ann Fam Med. 2020;18(3):196-201, the following disclosure was inadvertently omitted: Part of the funding for Neil Korsen, MD comes from the Maine Lung Cancer Coalition, a statewide effort funded by Bristol Myers Squibb Foundation, Maine Cancer Foundation, Maine Economic Improvement Fund, and Anthem Foundation. 